\title{
Fusion cash shortfall leaves JET grounded
}

Jim Giles, London

One of the world's premier fusion experiments - the Joint European Torus (JET) reactor in Oxfordshire, UK - may have to shut down within the next few years, researchers and officials say.

JET's future is in doubt because the current fusion budget at the European Union (EU) cannot both support the continent's present fusion projects and pay for the construction of ITER, the planned international magnetic fusion reactor.

ITER is expected to take about a decade to build. And closing JET such a long time before ITER is operational would severely disrupt preparations for the new reactor, critics of the closure proposal contend.

Some $€ 200$ million (US\$230 million) of the EU's $€ 750$-million fusion budget for 2002-06 has been earmarked for ITER's construction. If work begins before 2006, officials will have to cut funding to existing projects to make ends meet. Because JET consumes the single biggest chunk of EU fusion money - about $€ 55$ million per year — researchers fear that it may be selected for closure. "There is a possibility that JET will have to close by 2006," confirms Pascal Lallia, an energy adviser with the European Commission's research directorate.

Fusion researchers accept that cuts must be made to allow ITER to be built, but they are split on whether JET should be spared. Supporters point out that JET is the closest in size to ITER of Europe's fusion reactors, and is the ideal place for fusion scientists to work while ITER is being built. "JET could help develop a generation of fusion researchers to run ITER," says David Baldwin, head of fusion research at General Atomics in San Diego, California.

Others note that research at JET over the

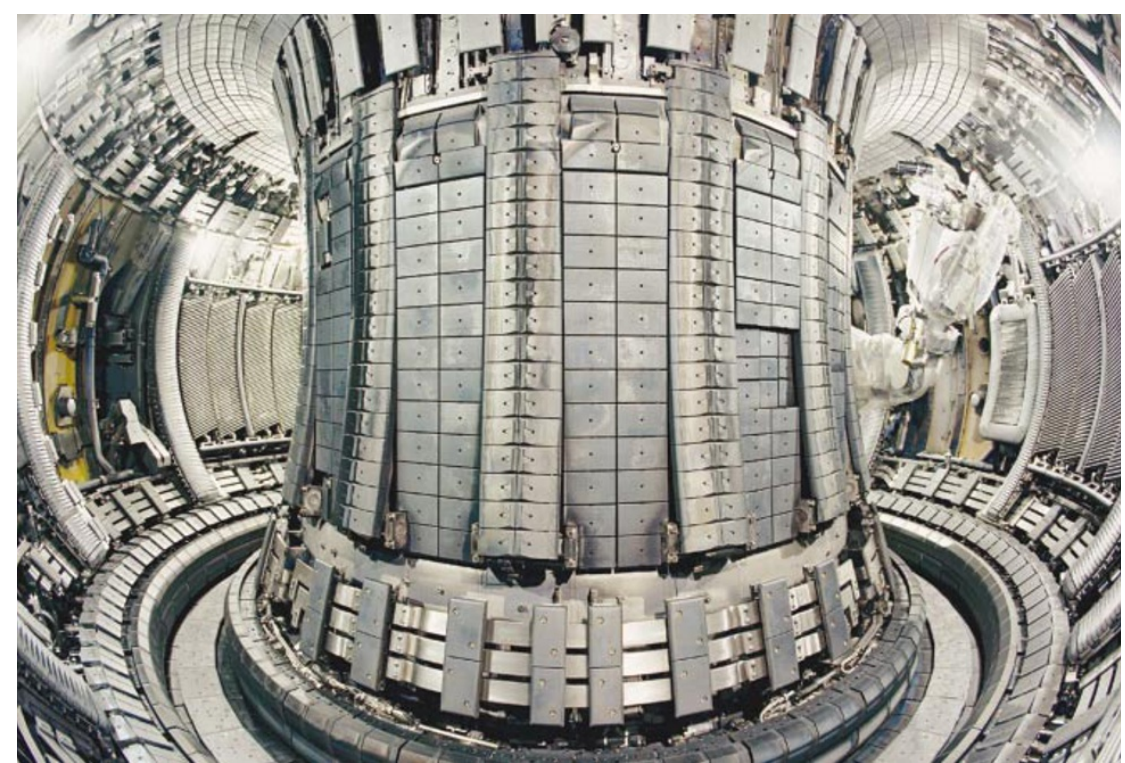

Under threat: the Joint European Torus fusion reactor may be forced to shut down by 2006.

past decade has helped to streamline ITER's design. Future experiments at JET, to increase understanding of the turbulence in the plasma contained in the reactor and how to control it, for instance, are likely to help guide ITER's early work, they add. "It's in the collective interest of European fusion researchers to keep JET going," says Steven Cowley, a plasma physicist at Imperial College London.

But shutting JET might be simpler than cutting funds to several of the 12 other national fusion projects that receive money from the same EU funding stream, and which could also be used to train researchers for ITER. "In an ideal world we would keep JET going," says Alexander Bradshaw, scientific director of the Max Planck Institute for
Plasma Physics in Garching, Germany. "But if we are short of money for financing the EU contribution to ITER construction, it would be more sensible to shut it."

Negotiations about which facility to close will begin in earnest once a site has been chosen for ITER, which received a boost last week when South Korea announced that it would be joining the project. An expert group of scientists and engineers, led by David King, the UK government's chief scientific adviser, is assessing the merits of proposed sites in France and Spain and will report in September. ITER's international partners will then compare the European site with two others in Canada and Japan, and a final decision could be made by the end of this year.

\section{Anger mounts over cutbacks at US army pathology lab}

\section{Erika Check, Washington}

Scientists at a military medical facility in Washington DC have lashed out at plans by the Department of Defense (DOD) to cut back on both its staff and its unique mission.

Observers say that the cuts, at the Armed Forces Institute of Pathology (AFIP), would also affect thousands of scientists and clinicians in non-military hospitals, who benefit from the institute's expertise.

"The AFIP is an incredible resource," says Darlene Ketten, a biologist at Woods Hole Oceanographic Institute in Massachusetts. "Their pathologists are the only ones I can send tissues to and know
I will get an answer affirmed by everyone in the research community."

The 60-year-old AFIP has an annual budget of $\$ 65$ million and 785 staff, based on the campus of the Walter Reed Army Medical Center and at several smaller facilities in the Washington area. It investigates US military casualties, as well as deaths that occur on government land. It was scientists at AFIP, for instance, who identified 178 of the 184 people killed during the terrorist attack on the Pentagon on 11 September 2001.

But scientists also use the AFIP's archive of materials and records from almost eight million deaths. For example, Jeff
Taubenberger, a molecular pathologist at the AFIP, used genetic material from lung tissue dating from the First World War to sequence the virulence genes of the deadly Spanish influenza virus (A. H. Reid, T. G. Fanning, J. V. Hultin and J. K. Taubenberger Proc. Natl Acad. Sci. USA 96, 1651-1656; 1999).

The DOD began scrutinizing the AFIP five years ago, when the institute claimed that it needed half-a-billion dollars to replace ageing buildings and equipment. The department found that it was subsidizing the AFIP's non-military work and in 2001 issued a report recommending that the AFIP either impose severe cost-saving measures or transfer some of its work to the 


\section{Studies assess risks of drugs in water cycle}

Quirin Schiermeier, Gothenburg

Antibiotics and other pharmaceuticals given to humans and livestock are increasingly contaminating rivers, groundwater and soils, according to early results from three European studies.

Drug-contaminated waste water is a potential risk to both human health and the environment, the studies' participants say. Treating sewage with ozone would be the best way of cutting the drug residues, they suggest.

Groups behind the three European Union-funded studies released their results at a Gothenburg press conference on 27 June. They reported that high concentrations of excreted antibiotics have been found in hospital and household sewage, slurry and water used for irrigation. Antibiotics and their metabolites also reach the environment directly from the urine and faeces of farm animals, the scientists find.

Researchers worry that the growing levels of antibiotics in the environment may damage ecosystems and fuel a surge in antibiotic

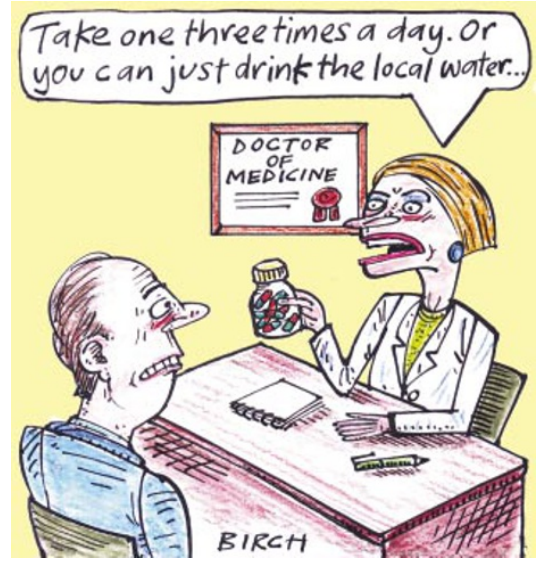

resistance among humans and animals. "Antibacterial resistance from farm animals can be transferred to humans, and is increasingly threatening the effective management of infectious diseases," says Wolfgang Witte, a microbiologist at the Robert Koch Institute in Wernigerode, Germany.

Officials at the European Union say the studies, and other similar ones, are likely to form the basis of new management procedures for medicines. Water companies and hospitals could also be required to take further steps to extract antibiotics from certain stages of the water cycle. This could be done, for example, by using separation techniques on the urine from hospital patients, and by injecting ozone into effluent at sewage plants.

Scientists involved in one of the projects, called Poseidon, found 35 pharmaceutical compounds, including five antibiotics, in the effluent of a local sewage plant in Braunschweig, Germany, and in local rivers. Concentrations in the effluent reached several micrograms per litre, with those in rivers and groundwater measuring 1.0-2.5 micrograms per litre, depending on the compound. Measurements taken at sewage plants in Poland, Switzerland, France and Austria revealed similarly high drug concentrations.

"Concentrations were particularly high in small rivers and streams that take a large amount of municipal waste water," says Thomas Ternes, a chemist at Germany's Federal Institute of Hydrology, and project coordinator of Poseidon.

In a parallel project, called ERAVMIS, researchers in Denmark, the Netherlands, Britain and Spain assessed the fate of veterinary medicines in slurry, made from manure, that is applied to the land as fertilizer.

Department of Health and Human Services.

In response, AFIP leaders told their staff this spring that they plan to save $\$ \mathbf{6 . 6}$ million a year by eliminating more than 100 jobs, and to slash the institute's \$3.5-million rent bill by closing three of its five facilities. They also decided to raise consultation and training fees, so that by 2004 the AFIP's military responsibilities would outweigh its civilian workload.

But AFIP staff claim that they were not consulted on the proposed changes, and many are strongly opposed to them. "I understand they had to make cuts but the way they proposed to do it was just malicious," says Renu Virmani, chair of cardiovascular pathology at the institute. Critics add that the plan will damage the AFIP's ability to retain expert pathologists by restricting its activities in non-military research.

Renata Greenspan, a pathologist at the Walter Reed Army Institute of Research who became director of AFIP in May, is re-evaluating the business plan, and says that she has worked hard to include the institute's staff in the process. She says that she has not determined what combination of staff reduction, rent cuts and increased charges will be necessary, and expects to present a new plan to the AFIP's divisional heads at the end of this month.

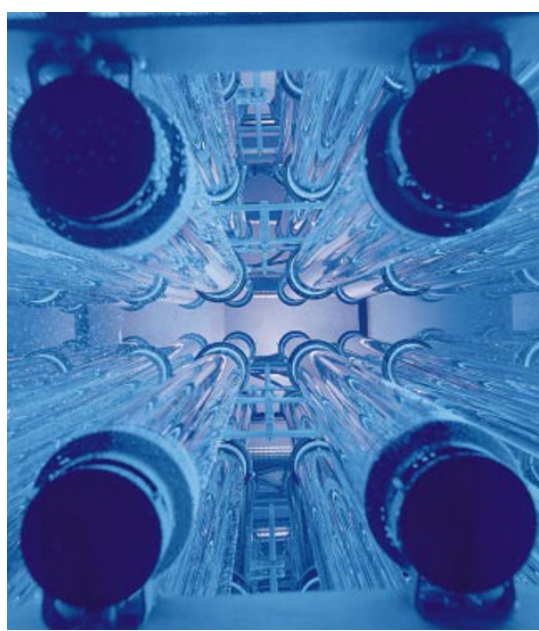

Ozone treatment such as that used on drinking water (above) could strip drugs from sewage.

They found that tetracyclines, a group of antibiotics widely used in livestock, cling to soil, degrading slowly. Concentrations remained high six months after application.

A third project, carried out by researchers in Sweden, Greece, Italy and France, also monitored effluents from sewage plants.

"There is clear evidence that some veterinary antibiotics persist in soils, and can move to rivers and streams and enter groundwater," says Alistair Boxall, an environmental chemist at Cranfield University, UK, and project coordinator of ERAVMIS.

The environmental effects of these compounds remain unclear, however. Researchers found no acute toxic effects on crops, worms, insects or fish. But they did find adverse effects on soil bacteria and some aquatic plants.

"Antibiotics can change the growth, enzyme activity and diversity of soil microbes," says Boxall. This may lead to a larger ecological problem, he adds, "but we don't know how big it is". More research is needed to determine whether microbial pathogens are becoming resistant to standard antibiotics, he says.

One recent analysis of raw sewage at the University Hospital of Würzburg, Germany, found that concentrations of antibiotics were not high enough to allow the selection of pathogenic bacteria resistant to them (K. Ohlsen et al. Environ. Microbiol.; in the press). But risks cannot be discounted on the basis of this result, says study co-author Thomas Ternes, a chemist at Germany's Federal Institute of Hydrology in Koblenz.

Ternes, the project coordinator of Poseidon, suggests that 'ozonation' of sewage is the most efficient way to eliminate unwanted residues. Ozone can be readily extracted from air, and it breaks down $99 \%$ of antibiotics and other drugs, he says. 